\title{
Evolution by Example
}

\author{
Adam M. Goldstein
}

Published online: 20 February 2008

(C) Springer Science + Business Media, LLC 2008

Keywords Evolution • Bibliography • Case study • History of evolution

\section{Introduction}

William Strunk and E. B. White, in their famous book The Elements of Style, suggest, in rule 16 (one of the "Elementary Principles of Composition") that a writer ought to always "use definite, specific, concrete, language."

Prefer the specific to the general, the definite to the vague, the concrete to the abstract....The greatest writers-Homer, Dante, Shakespeare-are effective largely because they deal in particulars and report the details that matter. Their words call up pictures. If the experiences of Walter Mitty, of Molly Bloom, of Rabbit Angstrom have seemed for the moment real to countless readers... it is because the details used are definite, the terms concrete....[A]ll the significant details are given, and with such accuracy and vigor that readers, in imagination, can project themselves into the scene (Strunk and White 2000, 21-22).

Strunk and White believe that this advice is not limited to literary writing, extending it to "exposition and... argument," in which "the writer must likewise never lose hold of the concrete," adding that "even when dealing with general principles, the writer

A. M. Goldstein $(\varangle)$

Department of Philosophy, Iona College,

715 North Avenue, New Rochelle, NY 10801, USA

e-mail: agoldstein@iona.edu must furnish particular instances of their application" (Strunk and White 2000, 22). A number of books on evolutionary biology are written in a manner conforming to this advice: The central device their authors use to explain general principles about evolution is an example. For this reason, I call the genre evolution by example. My aim in this essay is to describe the nature of this genre, to point readers to some exemplary works in it, and to argue for its importance.

\section{What is Evolution by Example?}

The defining characteristic of works of evolution by example is that they aim to bring their readers to an understanding of the general by way of an extensive account of the specific: They build their central explanatory scheme around a case study. This strategy, rather than a particular topic within evolutionary biology, is what distinguishes evolution by example from other types of writing about evolution. As will become evident below when some touchstones of the genre are pointed out, such case studies may be classified in a variety of ways, and there is probably no one correct way to group the works of evolution by example: Some case studies concern the evolution of a particular species, evolution in a particular locale or kind of environment, or the evolution of a striking trait.

Although the strategy of explanation of evolution by example is its stylistic hallmark, these works have an aim that transcends the particular: They aim at explaining general characteristics of processes (mechanisms) of evolution that are central to the theory of evolution. On the one hand, "evolution" is sometimes used to describe the history of life, as in "One of the most 
important events in evolution was the extinction of the dinosaurs" or "The move to land by vertebrates represented a key point in their diversification." On the other hand, the theory of evolution describes kinds of processes of evolution, or, to use another term for "processes," mechanisms. These processes (mechanisms) include (but are not limited to) mutation, natural selection, random drift, sexual selection, and speciation. "Theory" here is not intended to suggest uncertainty or lack of confidence. Rather, like "theory of gravitation," "theory of evolution" is intended here to indicate the set of natural laws and well-established facts that describe and explain why and how the history of life has occurred as it in fact did and predict how it will occur in the future.

Works of evolution by example may be contrasted with textbooks such as Futuyma's classic Evolutionary Biology (Futuyma 1986), Roughgarden's Theory of Population Genetics and Evolutionary Ecology (Roughgarden 1979), and Gillespie's Population Genetics: A Concise Guide (Gillespie 2004). Although their explanatory aim is much the same as that of works of evolution by example-to explain the theory of evolution-their strategy is different: They present general claims, recruiting examples only occasionally, and treating them in far less detail than they would be treated by a work of evolution by example. Indeed, evolution textbooks seem to share a common pool of three or four stock examples: variation in alcohol dehydrogenase genes; human blood types, in general and in the case of sickle-cell anemia, and, of course, Mendel's pea plants. These serve as work for students and as a demonstration of the direct application of theoretical principles.

Many trade paperbacks about evolution that are directed at a general audience may also be contrasted with evolution by example. For instance, consider Richard Dawkins' The Selfish Gene (Dawkins 1989), The Extended Phenotype (Dawkins 1982), and The Blind Watchmaker (Dawkins 1987). The aim of these books is to explain and argue for the importance of general notions: the selfish gene, the extended phenotype, and the idea that complexity does not require a designer. The function of examples in these works is to show that these general claims are not completely empty of real-world content. They do not establish the utility of these notions for observation and experiment or even for further theorizing. This work is left to others who, Dawkins hopes, are able to grasp them sufficiently to use them in their own work.

Similarly, a book such as Sean Carroll's Endless Forms Most Beautiful (Carroll 2005), which is about an entire discipline-"evo-devo," the study of the evolution of developmental processes-treats examples in a cursory manner, in contrast with how they are treated in works of evolution by example. The central problems motivating evo-devo and the way in which its general principles and methods are used to solve those problems are central to Carroll's work; examples illustrate the progress that evo-devo has made, but are not intended to provide an initial intellectual point of access to its central principles. Stanley's New Evolutionary Timetable (Stanley 1981) and Eldredge's Time Frames (Eldredge 1985) should be viewed similarly. They aim to explain and provide evidence for a general theory, punctuated equilibrium, adducing examples for proof rather than taking them as a primary explanatory device.

Case studies offer creators of works of evolution by example a range of excellent opportunities not afforded to creators of general works. In the hands of a skilled and imaginative writer, accounts of the people, places, discovery, and confirmation of facts and principles about their subjects can be parlayed into a compelling story in which the "resolution" of the "plot" is the discovery and elaboration of general principles of evolution that pertain to the example. In the great tradition of Darwin's own Journal of Researches (Darwin 1845) ("Voyage of the Beagle"), many works of evolution by example present particular locales as central themes. These locales are typically exotic, rugged, and beautiful, including (among others) the Galápagos Islands, Lake Victoria, and the Australian Outback. They often also concern the early generations of evolutionists. The voyages of these scientists around the globe and the reader's imagined voyages in time to the late nineteenth or early twentieth century form the backdrop of an intellectual voyage. The scientist-protagonist struggles with the elements and distance from home; but most of all with the subtleties of new kinds of arguments, new kinds of evidence, and the understanding of new truths about biological diversity. Often, the scientists' struggles in the academy run parallel to their ocean voyages and cross-country treks. The seminar room, the vaulted halls of museums in Europe, Britain, and America, and the international scientific literature create the ideal setting for which what Michael Ruse aptly terms "science red in tooth and claw" (Ruse 1999).

Works of evolution by example are primarily published as trade books, even those published by university presses. For instance, Harvard University Press published Elisabeth Lloyd's Case of the Female Orgasm (Lloyd 2005). This book, subtitled "bias in the science of evolution," surveys competing explanations for the 
female orgasm as a means of investigating the nature and applicability of explanations invoking natural selection. Lloyd's book is shelved on thefirst floor of the Mid-Manhattan branch of the New York Public Library, among popular recent works about women's sexuality: The first floor stacks are for those on a lunch break or on their way home from work to browse, in contrast with the higher floors, where scholarly monographs are kept. Some works of the genre are recognized as exemplary works of general interest: Jonathan Wiener's The Beak of the Finch (Weiner 1994) won the 1995 Pulitzer Prize for general nonfiction.

Although written for a general audience, works on evolution by example have much in common with scholarly books. Most are written by professionalseither university faculty in Humanities disciplines such as history or philosophy, or scientists engaged in active research-and most reflect the current research work of the author. The Beak of the Finch, written by a journalist, is an exception. Like scholarly monographs, works of evolution by example typically provide detailed bibliographic information for scholarly work in science, history, philosophy of science, or primary sources in the history of science. Evolution by example is, on the whole, a sober discipline, written in an observant, thoughtful tone, even in works narrated in the first person in the style of a memoir or travel journal. The central character, intent on reporting the scene as it is, remains circumspect throughout, delivering his or her conclusions only as evidence warrants.

The connection of evolution by example with scholarship and truth, together with its narratives of scientific discovery and the human side of scientists themselves, points to a further effect typical of works in the genre. They aim to represent science as an empirical discipline that is in constant motion, rather than as a settled body of fact or a set of received views accepted on authority or faith. This does not mean that they aim to generate skepticism about science, for instance, advocating the view that science does not aim at or occasionally discover truth because its claims are always provisional. Rather, these books aim to portray science as a growing body of knowledge in which hard-won insights are modified, supplemented, and extended by further theoretical and empirical study in the years and decades after an initial discovery or novel idea. Scientists are portrayed as being at their best when they transform their intellectual tradition, sometimes at great personal cost or risk to their lives and reputations-as opposed to protecting a sinecure or defending a received view.

Because they describe people and institutions in so engaging a manner, works of evolution by example have lasting value. As science does move on (if not progress), explanations presented by narrators, historical personages, or today's scientists in works of evolution by example will inevitably be modified, displaced, or even discarded in light of new discoveries and conceptual changes in science. Nonetheless, I anticipate that works of evolution by example will hold the interest of the reading public for a long time. The specificity and richness in detail that distinguishes them from other science writing results provides them with an internal coherence and robustness in much the same way that the great literature of past ages still moves us today. As readers share the experiences of the narratives' protagonists, they feel the grip of the scientific challenge and the evolutionary reasoning used to meet it. The scholarship typical of a work of evolution by example discussed above makes it that much easier for them to age gracefully; the curious reader can research the fate of the sources that form the basis for the work's scientific and historical claims.

\section{Evolution by Example-by Example}

In keeping with the theme of this essay, I would now like to point to some touchstone works of evolution by example. As I suggest above, I do not think that there is any single best way to classify the works of the genre; here, I indicate exemplary works from a three-part division of the genre into categories that I think will help the student of evolution focus his or her interest: works about sex; works about evolution in particular locales; and works about strange, wonderful, and intriguing animals.

\section{Sex}

Sex-understood broadly, as the exchange of genetic material among individuals-is almost universal among species, an enigma that has long puzzled evolutionary biologists. Why is there so much sex? What is it good for? Why has natural selection promoted, or at least permitted, the spread of sexual reproduction? The question is even more pressing in light of the range of adaptations for success in sex seen across the plant and animal worlds. The touchstone work of evolution by example in this category is Dr. Tatiana's Sex Advice to All Creation: The Definitive Guide to the Evolutionary Biology of Sex (Judson 2002), by Olivia Judson, an Oxford Ph.D. in evolutionary biology. 
As its title suggests, the book concerns the evolution of the mating behavior of a wide range of organisms: ${ }^{1}$ it is a work about evolution by example in virtue of the many dozens of case studies Judson uses to offer readers an entreé to evolutionary reasoning and explanation. In what is quite literally a perverse turn on Ann Landers and Dear Abby-but a page right out of Dr. Ruth - the central premise of the book is that the animals of the world, experiencing problems in their love lives, or perhaps simply bewildered by the sexual behavior of their own species, write letters requesting advice from Dr. Tatiana, an expert in the evolutionary biology of sex. Dr. Tatiana distills her encyclopedic knowledge of evolutionary science into a pithy, witty response to each bewildered creature, explaining the latest thinking on why it is reasonable to believe that the behavior inquired about evolved by natural selection. She is always careful to point out what uncertainties remain, and the answer to each animal's question is amply documented.

For instance, at the start of chapter 6, "How to Make Love to a Cannibal," she offers the following sensible advice. "Rule number one: Never get eaten during foreplay." This advice is particularly germane for male European praying mantises. A female of the species, who signs her letter "I Like'm Headless in Lisbon," fearing that she is abnormal for her kind, contributes a query about what appears to be rather extreme behavior.

I'm a European praying mantis, and I've noticed I enjoy sex more if I bite my lovers' heads off first. It's because when I decapitate them they go into the most thrilling spasms. Somehow they seem less inhibited, more urgent—it's fabulous. Do you find this too?

In answer to "Do you find this too?" the modest Dr. Tatiana writes, "Some of my best friends are maneaters, but between you and me, cannibalism isn't my bag." She then explains why natural selection might favor such behavior. As she demonstrates with further examples, the central rationale behind "Rule Number One" is that, if one partner is eaten before fertilization ("during foreplay"), that partner will most likely not be able to transmit any genetic material to the next generation. After fertilization, of course, the situation is different. As Dr. Tatiana explains, on the whole, the situation is rather complex. Availability of food sources

\footnotetext{
${ }^{1}$ The title's use of "all creation" notwithstanding, the botanically inclined will be disappointed to learn that all of the organisms discussed are animals.
}

also plays a role, as one might naturally imagine, and those with potentially cannibalistic mates have evolved safeguards that increase their chances of surviving to another mating season.

"Like'm Headless" is just one of many letter-writers in "How to Make Love to a Cannibal," each presenting a new situation in which sex and death are linked, and by the end of the chapter, a reader will easily have in hand a general account of the circumstances in which sex finishes with a meal of one's mate. The other chapters similarly provide knowledge that is at once broad and deep about other aspects of the evolution of sex. At the same time as it informs and entertains, Judson's choice of examples and her ability to characterize them in terms of human sexuality create a subtle effect. Judson observes that monogamy is rare in nature, and virtually all of the sexual behaviors Judson discusses would be considered perverse, if not criminal, if practiced by a human being. The cumulative effect of these examples is that the reader is faced with the question of how and why human sexual behaviors, which are endowed with personal and cultural meaning, differ from those of the animals. Against the backdrop of sex as it is found in nature, the sexual practices we often take to be normal are in fact highly unnatural.

Given the prevalence of sex in nature and the attention that it has received from evolutionists, there are relatively few works of evolution by example about it. Besides Judson's work, the most notable are Helena Cronin's The Ant and the Peacock (Cronin 1991) and Lloyd's book, already mentioned, The Case of the Female Orgasm (Lloyd 2005). In light of the paucity of evolution by example on this topic, science writers should feel that the gauntlet-or rather the bodice?-is thrown down.

\section{Exemplary Places}

Some writers introduce an exotic, dangerous, or remote place far from home as a central character in their works of evolution by example. This central character plays many roles: a destination to be attained by days or weeks of travel, a place to meet new people and experience other ways of life, and an enemy of creature comfort, health and hygiene, and life and limb. Beyond this, places play an even more important role: the stage on which an evolutionary play is performed, with evolutionary biologists present as an audience sensitive to every nuance of the acting and set. The touchstone of evolution by example concerning place is Jonathan Weiner's Beak of the Finch (Weiner 1994), a work about evolution on the Galápagos Islands, themselves an icon of evolution. 
The central subject of Weiner's book is the work of Peter and Rosemary Grant, Princeton University scientists who have been observing Galápagos finches for many decades. The island environment has special advantages for observing birds. As many of the islands are small, it is possible in some cases to identify almost every bird that lives on a particular island and the offspring of each, constructing highly accurate family trees. It is also possible to collect detailed, comprehensive information about the characteristics of the island habitats on the smaller islands. Using this information, the Grants have been able to observe changes in the beak shape and size of many finches and to understand how those changes have been shaped by natural selection.

The Beak of the Finch almost stands on its own as a story of exploration, taking the reader on repeated trips with the Grants to the Galápagos. Weiner also brings the reader back in time, reconstructing Darwin's initial trips to the islands and presenting the history of the ornithologist David Lack's pioneering work in the islands in the early 1940s, on a research expedition sponsored by the California Academy of Sciences. Just as a scientist returns to the lab or the library to reflect on his or her fieldwork, Weiner reports from the Grants' labs and offices in Princeton and similarly visits with Darwin and Lack after they return home, where they contemplate the meaning of their observations for the general theory of evolution. The Galápagos finches form the starting point for Weiner's broader discussion of evolution and its consequences for contemporary life. This discussion touches on the evolution of pesticide-resistant insects, which develop as a result of natural selection, and the evolution of the AIDS virus. The Beak of the Finch is extensively documented for the reader who wishes to learn more or to verify Weiner's claims.

Readers should be aware of another important work about evolution in the Galápagos, Evolution's Workshop (Larson 2001). Authored by another Pulitzer winner, the University of Georgia history and law professor Edward J. Larson, this work may be regarded as a supplement to Weiner's book. Evolution's Workshop explores the cultural and historical meaning of the Galápagos in political and idealogical struggles over evolutionary biology, offering a historical and religious perspective on the importance of the famous archipelago.

Two other works serve as touchstones of evolution by example that concern the theme of place. George Gaylord Simpson's Splendid Isolation: The Curious History of South American Mammals (Simpson 1980) takes the entire South American locale as its central example. Simpson brings the reader on a kind of paleontological travelogue-safari through the extinct mammals of South America, many of which seem like they would be quite at home with the whimsical creatures cared for by Dr. Doolittle. The central evolutionary theme of the book is the relevance of geography and distance in explaining the differences between North and South America. Splendid Isolation has a companion, Simpson's Discoverers of the Lost World (Simpson 1984), a historical account of the scientists who discovered many of the fossils described in Splendid Isolation.

Tijs Goldschmidt's Darwin's Dreampond: Drama in Lake Victoria (Goldschmidt 1996) is also strongly recommended for those intrigued by other places. Goldschmidt, an ichthyologist, describes his experiences traveling to Lake Victoria to study cichlid fishes. These fishes exist in approximately 150 species in Lake Victoria, and new species are still being discovered there with regularity. These species have formed very rapidly, so that daughter species often coexist with their ancestors in the lake, to which the cichlids have been confined for many thousands of years. Because of this, it is possible to determine relationships of ancestry among them. Exciting simply for its account of the fishing lifestyle of the people who live near Lake Victoria, Darwin's Dreampond touches on the interrelationships among the various evolutionary processes, highlighting the origin of species.

\section{Strange Creatures}

The third and final category of works of evolution by example I will consider in this essay contains those works that take extraordinary animals as their central subject. Three touchstone works exemplify this subgenre. The first, Ann Moyal's Platypus: The Extraordinary Story of How A Curious Creature Baffled the World (Moyal 2004), concerns a creature that is itself a touchstone of nature's strangeness: the platypus. As is well known, the platypus bears traits distinctive of birds and mammals alike. Anyone who has a minimum of experience with the elusive critter knows that it is a particularly nonthreatening sort of animal, although the males are able to administer a harmful sting with their feet. Whatever the danger posed by its stinger, the platypus is one of the few animals whose very existence has posed a mortal threat to an entire human conceptual framework. The hodgepodge anatomy and lifestyle of the platypus offered a significant challenge to the notion that organisms fit neatly into hierarchically arranged, mutually exclusive classes. Charles Darwin, in his pre-evolutionary days, understood the platypus's significance, as indicated by an 1836 statement of his reproduced on the back cover of Moyal's 
book. "A disbeliever in everything beyond his own reason might exclaim, 'Surely two distinct creators must have been at work." "

Platypus is structured as a history of the discoveries and theories about the platypus, starting with the first encounters of European and British explorers with the platypus in the late eighteenth century. In the early years of platypus science, placing the platypus in the correct taxonomic category was a matter of national pride among English and continental scientists, who vied for specimens and engaged in a cross-channel war of words in scholarly journals. There were the usual questions about the ecology and behavior of the platypus, but the most pressing questions were those whose answers might decide which taxonomic category the platypus ought to be placed in. Does the platypus suckle its young-and if so, does the "duck bill" of the young platypus interfere? Does the female platypus have mammary glands? Finding specimens was difficult because access to platypus habitats required backcountry travel, and moreover, once in platypus country, the stealthy, shy platypus was difficult to sight and even more difficult to capture, alive or dead. Moyal describes the toils of English platypus hunters who explored the Australian bush, attempting to locate specimens to send back to England alive. Most of the captive animals died before making it to the ships that were to take them abroad. The cause of death seems to have usually been hunger; Moyal (Moyal 2004, 187) reports that a platypus can eat more than half its body weight in grubs in one night. The story continues to the present day. The adaptations of the platypus are still being discovered by Australian scientists, who see the uniqueness of their object of study as a point of national pride.

Another book worthy of note in the category of "strange creatures" is Samantha Weinberg's A Fish Caught in Time (Weinberg 2000), which concerns the coelacanth, discovered in the late 1930s. This fish, which seems to have stopped evolving some hundreds of millions of years ago, exhibits some skeletal features of animals of the kind that made the move to land, providing insight into how the fins of early fishes were transformed into limbs suitable for walking. Like Moyal, Weinberg tells the story from a historical perspective. Marjorie Courtenay-Latimer, working as the sole curator of a one-room museum in East London, South Africa, found it in a fisherman's net, along with a haul of sharks; immediately realizing that it was a novel find, she brought it back to her museum from the docks in the trunk of a taxicab. She contacted ichthyologist J. L. B. Smith, who was able to confirm that the fish she had found was not of any known species and that it had primitive features. Although not scientifically current,
Smith's 1956 Old Fourlegs (Smith 1956) gives a sense of the excitement that the discovery caused at the time.

Stephen Jay Gould's Wonderful Life: The Burgess Shale and the Nature of History (Gould 1989) is a third touchstone work of evolution by example in the "strange creatures" category. Gould considers the fossil creatures of the Burgess Shale, a mountainside assemblage of fossilized animals that, some 500 million years ago, inhabited what was once an ocean floor in a region now in the Canadian Rockies. These creatures are nothing like those of today, and there are many more species in the small area of the shale than are represented in vastly larger areas of today's sea bottoms that have a similar density of organisms. Moreover, none of these strange forms now exist, and none are ancestors to any existing lineage. Gould takes this lost world of diversity as a starting point for his arguments about whether the history of life represents progress and his meditations on the influence of chance in evolution.

Finally, George Gaylord Simpson's Horses: The Story of the Horse Family in the Modern World and Through Sixty Million Years of History (Simpson 1951) is a work of evolution by example that is not about a strange creature, but rather, a familiar and much-loved one. This book is not scientifically up-to-date; nonetheless, it provides the framework for contemporary studies of the evolution of horses, which remain a central organism of study among paleontologists. Because it is so central to the current discussion in paleontology, interested readers will not have any trouble following up Simpson's work with more current references. Horses differs from the other works discussed in this essay because it is a scholarly monograph rather than a trade publication; it will make slow going for those not already familiar with basic ideas about evolution and a good understanding of anatomy. It is a classic of twentieth century evolutionary biology and well worth the effort for those looking for a more advanced text.

\section{The Importance of Evolution by Example}

Works of evolution by example are valuable in themselves as models of literary style, stories of human endeavor, and as a link between the scientific community and the public at large. Because evolution stirs up controversy, however, they have additional value as a tool for bringing about an understanding of that subject among those otherwise not familiar with it or reluctant to accept it. The audience that I believe that evolution by example will most likely have this effect on is the great mass of people that are open to reason concerning 
whether evolution has occurred, but do not understand what it means to accept this claim.

These people trust science, recognizing, for instance, that it forms the basis for clinical medicine and that its predictive power is extraordinary. As well, they recognize that the institutions of science are designed to discover truth (if only in the long run). At the same time, it is difficult for them to imagine how a process, absent the intervention of a designer, could have produced complex adaptations and the diversity of life. What is the chance that, say, the vertebrate eye evolved? That a protein form, from a primordial stew of amino acids? These abstractions boggle the mind. Marjorie Courtenay-Latimer hauling a coelacanth from the docks to the museum does not. Nor does the identification of a platypus' mammary glands by nineteenth century scientists or the discovery of a new Burgess Shale fossil. These are the accomplishments of wellmeaning people, trained in the science of their day, whose work has been confirmed by those of subsequent generations. The mind's eye focused on a rich view of the particular, the reader of evolution by example gains mastery over a single case, which in turn orients him or her to the general principles of evolutionary biology. This is in accord with a central principle of scientific method: Science is an empirical discipline, its conclusions only as strong as the experiences on which they are based; science, in François Jacob's nice phrase, "looks for partial and provisional answers about those phenomena that can be isolated and well defined....Although asking general questions [leads to] to limited answers, asking limited questions [turns] out to provide more and more general answers" (Jacob 1977). ${ }^{2}$

\section{References}

Carroll SB. Endless forms most beautiful: the new science of evo devo and the making of the animal kingdom. New York: W. W. Norton \& Co.; 2005.

Cronin H. The ant and the peacock: altruism and sexual selection from Darwin to today. New York: Cambridge University Press; 1991.
Darwin C. Journal of researches into the geology and natural history of the various countries visited by the H.M.S. Beagle round the world, under the command of Capt. Fitz Roy, R.N. 2nd ed. London: John Murray; 1845.

Dawkins R. The extended phenotype. New York: Oxford University Press; 1982.

Dawkins R. The blind watchmaker. Original ed. New York: W. W. Norton and Company; 1987.

Dawkins R. The selfish gene. New ed. Oxford: Oxford University Press; 1989.

Eldredge N. Time frames: the rethinking of Darwinian evolution and the theory of punctuated equilibria. New York: Simon and Schuster; 1985.

Futuyma DJ. Evolutionary biology. Sunderland, Mass: Sinauer Associates; 1986.

Gillespie J. Population genetics: a concise guide. 2nd ed. Baltimore: The Johns Hopkins University Press; 2004.

Goldschmidt T. Darwin's dreampond: drama in Lake Victoria. Cambridge: MIT Press; 1996.

Gould SJ. Wonderful life: the Burgess Shale and the nature of history. New York: W. W. Norton; 1989.

Jacob F. Evolution and tinkering. Science 1977;196:1161-6.

Judson O. Dr. Tatiana's sex advice to all creation. New York: Henry Holt and Company; 2002.

Larson EJ. Evolution's workshop: God and science on the Galápagos islands. New York: Basic Books; 2001.

Lloyd EA. The case of the female orgasm: bias in the science of evolution. Cambridge: Harvard University Press; 2005.

Moyal A. Platypus: the extraordinary story of how a curious creature baffled the world. Baltimore: The Johns Hopkins University Press; 2004.

Roughgarden J. Theory of population genetics and evolutionary ecology: an introduction. New York: Macmillan; 1979.

Ruse M. The Darwinian revolution: science red in tooth and claw. 2nd ed. Chicago: University of Chicago Press; 1999.

Simpson GG. Horses: the story of the horse family in the modern world and through sixty million years of history. New York: Oxford University Press; 1951.

Simpson GG. Splendid isolation: the curious history of South American mammals. New Haven: Yale University Press; 1980.

Simpson GG. Discoverers of the lost world: an account of some of those who brought back to life South American mammals long buried in the abyss of time. New Haven: Yale University Press; 1984.

Smith JLB. Old fourlegs: the story of the coelacanth. London, New York: Longmans, Green; 1956.

Stanley SM. The new evolutionary timetable: fossils, genes, and the origin of species. New York: Basic Books; 1981.

Strunk W, White EB. The elements of style. 4th ed. Boston: Allyn and Bacon; 2000.

Weinberg S. A fish caught in time: the search for the coelacanth. New York: HarperCollins; 2000.

Weiner J. The beak of the finch: the story of evolution in real time. New York: Knopf; 1994.

\footnotetext{
${ }^{2}$ I would like to thank Philip Yockey of the New York Public
} Library for valuable comments on an earlier draft of this essay. 